\title{
Fantasy Animations and Children's Imagination: A Qualitative Study
}

\author{
Maryam Khaleghipour $^{1}$, Ehsan Shahghasemi ${ }^{2}$ \\ ${ }^{1,2}$ University of Tehran
}

\begin{abstract}
:
Fantasy animations give children the possibility to navigate through imaginary and fantasy worlds and immerse themselves in the story world. This paper attempts to show that children's experiences of the fantasy world have a significant effect on children's imagination about themselves and the future of the world. Therefore, semi-structured interviews were conducted with 65 children ( 35 girls, 30 boys) between 6-12 years old, and the children were interviewed in tow groups. Then, the interviews were analyzed, coded, and categorized. The results showed that for those children who watched fantasy animations a lot, imagination about the future of the world was a mixture of reality and fantasy; we found, also, that there was a big difference between their actual self and their ideal self. But children who watched fantasy animations less than three hours a day had a more realistic image about the future and there was a lesser difference between their actual and ideal selves. Importantly, children with heavy consumption of fantasy animations thought and imagined in the context of fantasy, and this deeply affected their perception of the future.
\end{abstract}

Keywords: Fantasy; Children; Cartoon; Animation; Iran 


\section{$2^{\text {nd }}$ International Conference on Future of SOCIAL SCIENCES and HUMANITIES}

\section{Introduction}

Television exerts a great effect on the cognitive, social, and emotional development of children. Although videos and computers are increasing in children's usage, television still remains the most ubiquitous medium among young children (Woodard and Gridina, 2000). Nowadays, children and adolescents watch more television than ever before (Shqair, Pauli, Costa, Cenci, \& Goettems, 2019). "The American Academy of Pediatrics recommends that children should be limited to 2 hours of TV per day and children under 2 years should not watch any television. Watching more TV and watching TV at a very young age have been associated with negative effects on cognitive development" (Helm \& Spencer, 2019: 241).

So much television exposure has been associated with the worries about the influence of television on the child's imagination. Singer (2003: 1) defined imagination as "the capacity to form images in one's mind of absent objects or to maintain thoughts or ideas without necessarily converting those into acts". Besides, some cartoon-based programs are fantasy and these types of cartoons are popular among children, and "in effect hypotheses TV is identified as the cause of changes in the viewer's fantasy life" (Valkenburg \& van der Voort, 1994: 317). Fantasy as Deutsch (1957) said, "is the illusionistic mode of the imagination and the literary or visual genre that is its product" (Brann, 1991: 21). Overall, popular children's television shows are most animated and contained little prosocial, violent or educational content, but frequently contain fantastical content (Taggart, Eisen, \& Lillard, 2019). When children engage with the fantasy they must imagine circumstances that do not exist and think if they did, what it would be like. Although some results show that such engagement facilitates learning (Weisberg \& Gopnik, 2013; but see Lillard et al., 2013; Lillard \& Woolley, 2015), it may also be cognitively taxing for children to orient themselves towards fantasy events, which are often surprising (because they are not encountered in real life) (Taggart, Eisen, \& Lillard, 2019). 


\section{$2^{\text {nd }}$ International Conference on Future of SOCIAL SCIENCES and HUMANITIES}

For this reason, in this paper, we wanted to know if there was any relationship between fantasy animations and children's imagination about themselves and the events in the real world. We wanted to know how did they saw themselves through the lenses of fantasy animations? We begin by describing the effect of television and fantasy on children's imagination, their play, and their selfdiscrepancy.

\section{Fantasy, Television, and Children}

Almost anybody who spends time around children can attest to the fact that they incorporate their favorite media texts in their everyday lives. Children talk about media texts, dress up, and engage in fantasy play based on these texts, create imaginary companions from them, make related artwork, and exhibit other behaviors that show the importance the media play in their lives (Gotz, Lemish, Aidman, \& Moon, 2005). One type of media program which children consume a lot is fantasy cartoons.

Fantasy is a powerful psychological process that enables human beings to create new ideas and concepts in their minds by building on existing ones (Gotz, Lemish, Aidman, \& Moon, 2005). At the same time, the concern over the potentially harmful impacts of mediated texts on the imagination and creative processes, particularly concerning children, also has roots in these early debates about fantasy. Plato, in ancient Greece, for example, perceived fantasy, images, and myths to be dangerously corruptive forces that shift the mind from conceptual thinking to the world of illusions (Brann, 1991). On the other hand, although videos, and computers are increasing in usage, television still remains the favored electronic media among young children (Woodard and Gridina, 2000). Therefore, we are interested to find if children who watch fantasy animations a lot, are influenced and these animations affect their imagination about the future and real life. We want also to know if these children's thoughts and predictions differ from children who do not consume so much fantasy animation. 


\section{$2^{\text {nd }}$ International Conference on Future of SOCIAL SCIENCES and HUMANITIES}

\section{Pretend play}

Pretend play is specific to human childhood. It is the one activity done by most children and done most by children (Sherrod and Singer, 1979). Pretend play is related to daydreaming. As Russ (2020) mentioned Singer (1975) defined daydreaming as thoughts that moved away from the external environment "toward an unfolding sequence of private responses to some internal stimulus" (p. 3), This unfolding sequence can involve memories, events, or creatively constructed images of future events. In pretend play, children express these internal thoughts and images (Russ, 2020). For this reason, singer (1981) defined pretend play as the externalization of fantasy. Both fantasy and pretend play have some process in common: the ability to form images, skill in storing and retrieving the formed images, a store of images, skill in recombining and integrating these images as a source of internal simulation and divorcing them from reality (Sherrod \& Singer, 2009). As some children watch fantasy animations a lot, we want to know Is there any relationship between children's pretend play and the story and images of animations?

\section{Self-discrepancy}

The person you would like to be like. This is the best question that helps researchers to found the characteristics that children like to have or find their hero (Havighurst, Robinson, \& Dorr, 1946).

For this reason, in this paper, we asked children about their ideal self, because we wanted to know if there was any relationship between watching fantasy animations and children's ideal-self. As fantasy isn't reachable, it can make a challenging situation in the future for children, if their idealself is not attainable in the real world. According to Higgins'(1987) theory of "self-discrepancy," there are three basic domains of the self: (a) the actual self, which is your representation of the attributes that someone (yourself or another) believes you actually possess; (b) the ideal self, which is your representation of the attributes that someone (yourself or another) would like you, ideally, to possess (i.e., a representation of someone's hopes, aspirations, or wishes for you); and (c) the ought self, which is your representation of the attributes that someone (yourself or another) 


\section{$2^{\text {nd }}$ International Conference on Future of SOCIAL SCIENCES and HUMANITIES}

believes you should or ought to possess (i.e., a representation of someone's sense of your duty, obligations, or responsibilities). This theory entails various results, such as: The greater the magnitude and accessibility of a particular type of self-discrepancy possessed by an individual, the more the individual will suffer the kind of discomfort associated with that type of self-discrepancy. This hypothesis was tested in a series of correlational and experimental studies. Consistent with the hypothesis, when either the magnitude or the accessibility of the subjects' discrepancy between their self-concepts and their ideal self-guides were greater, the subjects suffered more from dejection-related emotions (e.g., disappointment, dissatisfaction, sadness). When either the magnitude or the accessibility of discrepancy between their self-concepts and their ought selfguides was greater, the subjects suffered more from agitation-related emotions (e.g., fear, restlessness, tension).

\section{Literature Review}

Valkenburg and Voort (1994) studied the influence of TV on daydreaming and creative imagination. They reviewed different hypotheses about this topic and explained why TV might influence children's and adults' daydreaming and creative imagination positively (stimulation hypothesis) or negatively (reduction hypothesis).

Gotz, Lemish, Aeidman, and Moon (2005) argued that producers of media texts for children offer them a wide array of role models and narratives to use in their fantasies. Children used media characters in their fantasies but rarely adopted them completely. They felt free to make changes in the characters to suit their own needs. They imagined themselves in these characters' shoes and/or used the most attractive traits and behaviors of the original media characters.

Davies (1997) had a positive view on the effects of television on children. His book was unique in its use of children's accounts to explore their awareness of the submerged conventions of television 


\section{$2^{\text {nd }}$ International Conference on Future of SOCIAL SCIENCES and HUMANITIES}

genres, of their functions and effects, of their relationship to the real world, and of how this awareness varies with age and other factors.

Schmitz, Joiner \& Golds (2020) explored the effects of virtual reality on young children's understanding of the possible and the impossible. Children were asked whether fantasies were possible in real life and why/why not. Children in the VR group were more likely to correctly judge the possibility of possible events than children in the video group and they were more likely to incorrectly judge the possibility of impossible events than children in the video group.

\section{Methodology}

Considering the purpose of the present study which was to develop a theoretical framework for future research, this project uses semi-structured interviews as a qualitative research method for collecting data. This form of interview is a guided conversation in which the researcher seeks insights into the social worlds of participants through their perspective and encourages interviewees to share important themes that may be unanticipated by the researcher (Barrick, 2020).

Moreover, this method is suitable for the reconstruction of a personal theory (Fleck, 2017: 172). The interview with children consisted of 6 questions; 1- what are your favorite animations? 2- how much do you watch these animations a day? 3- what is your favorite play? 4- who is the person you would like to be like? 5- what do you think generally about? 6- what is the image of the future in your mind?

All the interviews with children were done in two schools. The first author decided to become a teaching assistant in the field under study for gaining further and accurate information. We thought it was necessary to be present in the field to observe children's behaviors closely. Thus, 10 days seemed sufficient to play the role of a teaching assistant to observe the children. In this context, we focused on studying the children ages 6 to 12 years old since, based on various studies, this age range is considered as childhood. 


\section{$2^{\text {nd }}$ International Conference on Future of SOCIAL SCIENCES and HUMANITIES}

One other issue was the number of samples: how long a researcher should continue sampling? Strauss and Corbin (2017: 230) expressed that data collection should be done until it reaches theoretical saturation and the categories are saturated. So, the number of the subjects in each group is different. When we reached theoretical saturation and the children's responses added no new data to the previous ones, a few more samples were taken for confidence, and then the interviews were stopped. Therefore, the interviews were conducted with 65 children ( 35 girls and 30 boys). For analyzing data, the "Grounded Theory" (1967) approach pioneered by Glacier and Strauss was employed. "The primary purpose of this design strategy is to evolve or "ground" a theory in the context in which the phenomenon under study occurs" (DePoy \& Gitlin,2016: 158). Grounded theory sets out to discover or construct theory from data, and this methodology is appropriate when little is known about a phenomenon (Tie, Briks \& Francis 2019).

According to Strauss and Glacier, "data sources in grounded theory should be interview and observation" (1994: 273) and the data from interviews and observations must be coded. We used open coding, axial coding, and selective coding to obtain themes and categories.

\section{Findings}

As mentioned, interviews were conducted with 65 preschools (6 years old) to sixth grade (12 years old) children. They were divided into two groups. The first group included children who watched fantasy-oriented animations a lot and the second group included children who watched fantasyoriented animations either a little or they did not watch at all. At first, the analysis of findings from the girls and then the answers and analysis of finding from the boys are provided. Based on the division of children in the two groups, 16 girls were grouped in the first group and the other 19 girls in the second group. An important point to be noted is how children's watching TV was measured by two words of "a lot" and "a little." The measuring method these two words was drawn from Singer's book (2005) in which children who watch their favorite programs for more than 3 hours a day are considered to be strong consumers and the children who spend less than 3 hours a day watching TV are grouped as low consumers. Therefore, the children were asked about the time 


\section{$2^{\text {nd }}$ International Conference on Future of SOCIAL SCIENCES and HUMANITIES}

they spend watching TV programs a day and their favorite programs, then they were grouped accordingly.

\section{Analysis of findings of girls}

\section{1- what are your favorite animations?}

The classification of the programs was done based on what has been explained in the theoretical part of the research. That is, the programs were examined one by one and those with high surreal and fantastic features were considered to be in the category of high fantasy programs (like Frozen and Spiderman), and the programs with relatively realistic features were grouped in the category of low fantasy programs.

\section{2- how much do you watch these animations a day?}

As we mentioned before, 16 girls watched fantasy animations more than three hours a day and 19 girls watched fantasy animations less than 3 hours a day.

\section{3- What is your favorite game?}

The purpose of this question was to understand if there was any relationship between animations that girls watched and their favorite games. The analysis of the data indicated that the difference in watching programs with high or low fantasy resulted in a difference in children's favorite games. While most girls had lots of commonalities in their favorite games, imitating the characters of the favorite programs was one of the favorite games for the children who watched fantasy animations a lot. They played it alone or with friends. Consider the following examples:

"I play the roles of Anna and Elsa. I wear a long scarf and freeze things with my hands" (girl, 6 years old)

"most of the time I play the roles of Anna and Elsa. I wish I could really be like them" (girl, 10 years old) 


\section{$2^{\text {nd }}$ International Conference on Future of SOCIAL SCIENCES and HUMANITIES}

The favorite games for other children who did not watch or rarely watched fantasy animations were imitating the real acts from real people like their mothers, sisters, and teachers or games with high levels of physical activity including cat and mouse game, hide and seek, and tag game.

Piaget believed that imitating games fall into two categories: first, the mental operations of verbal animating and animating by identifying and activating children's imagination. For example, a girl role-plays as her mother. Second, most children's imitating games, at least in Western culture, are drawn from the realm of fantasy and imagination. The animated mental images in children's games are mostly borrowed from the fantasy world they meet in stories, children's books, cinemas, television, and games (Ariel, 2002: 8-10).

\section{4- What do you think generally about?}

One of the ways to understand children's imagination is to know about their thoughts. With this question we could understand what was the common things that children imagined about, and if there was any relationship between their imagination and the animations they watch.

The results showed that 13 children of 16 who consumed fantasy-oriented animations a lot talked to unrealistic characters and thought about fantasy stories. Some of the children stated that they dream about their favorite characters and like them so much so that they did not like to wake up. Some younger children talked to their imaginary friends or their dolls during the day. Here are examples of children's talking about fantasy stories and characters they thought:

"I always like to dream about cartoons. Once, I was dreaming of a cartoon. My mom was calling me to eat dinner. I told her to let me sleep and I slept again. There's an animation in which there are creatures in a girl's mind and control her. I like to dream about that animation and be controlled by those creatures. I'd love them because they make me laugh. Or, for example, I role-played as Cinderella and then entered the cartoon. I went to the castle. Then, my mom woke me up. I told her I was dancing with the prince; why did you wake me up. My mom said, prince? What do you say, darling? I told her I was dreaming of Cinderella. I slept again and continued my dreaming” (girl, 9 years old) 


\section{$2^{\text {nd }}$ International Conference on Future of SOCIAL SCIENCES and HUMANITIES}

However, children who rarely watched fantasy-oriented animations or did not watch them at all were not interested in talking to themselves. Most children also thought about the near or far future. For example:

"Well, it depends. If I have an exam tomorrow, I'll think about my exam. If I have to go to school tomorrow, I think about what to do to answer the questions" (girl, 11 years old)

"most of the time I think about the exam I have tomorrow or my future opportunities. For example, can I really be accepted in university or be successful to be proud of myself?” (girl, 12 years old)

Only two children stated that they make imaginary stories or change the stories they watched. It should be noted that they watched fantasy-oriented animations more than the others in the group.

\section{5- Who is the person you would like to be like?}

The answers demonstrated that the children who watched more fantasy-oriented animations tended to, in younger ages, be like their favorite characters in cartoons but the children aged 8 and older liked to have some fantastic features or magical power in addition to their real personality:

"I like to have the power of Ralf because I like to fly very much and I like to have the power to help people. I like my current characteristic and I enjoy my life and my family but I like to have this power, too" (girl, 12 years old)

Concerning the children who rarely watched the fantasy-based cartoons, the results showed that none had a desire to become a fantasy character. They said they like what they really are, except two children who desired to be similar to another character; however, this character was not a fantasy one:

"I wish I have more achievements and become a better girl. I wish I could make a watch or something advanced that no one could have invented. Anyway. I like myself as I am now" (girl, 9 years old) 


\section{$2^{\text {nd }}$ International Conference on Future of SOCIAL SCIENCES and HUMANITIES}

\section{6- What is the image of the future in your mind?}

The previous question on children's desire to change, the children were asked whether they liked the world as it is or they have another image of a desired and ideal world in their mind. The study hypothesized that the children who watch fantasy animations would like the world to be like fantasy animations or have some dimensions of those environments. While the assumption was demonstrated in answers by some children, the children who watched fantasy animations a lot, liked to change the world based on reality. Consider the answers by children who tended to make a different world but based on reality:

"A world with a lot of trees, a lot of grass, with dinosaurs and many flowers" (girl, 6 years old)

"A world that is green everywhere. People are nice and happy. It's raining all the time and flowers are everywhere" (girl, 8 years old)

There wasn't any difference in the answers by the girls aged 11 and older. In fact, the children in both groups at this age level wished to change the world to make an improvement in health technologies and relationships among people. The difference was that the children who watched fantasy animations a lot had a mixed image of a world with fantastic (superhuman and magical power) and real elements. They indicated that in the future they will have some magical power and they can save the world and people with these powers. They also thought that some of the impossible things will be possible in the future, while the children in the second group had a more realistic view.

\section{Analysis of findings of boys 1- What are your favorite animations?}

The classification of the programs was done based on the same method described above. That is, the programs were examined one by one and those with high fantastic features were considered to be in the category of high fantasy programs (like Spiderman, Avengers, etc.), and the programs 


\section{$2^{\text {nd }}$ International Conference on Future of SOCIAL SCIENCES and HUMANITIES}

with relatively realistic features were grouped in the category of low fantasy programs. In general, 30 boys between 6 and 12 were interviewed; 17 in the first group and 13 in the second group.

\section{2- How much do you watch these animations a day?}

In general, 30 boys between 6 and 12 were interviewed; 17 of them watched fantasy animations a lot and 13 boys watched fantasy animations less than 3 hours a day or they rarely watched these types of animations.

\section{3- What is your favorite game?}

The results showed that the children who watched fantasy animations a lot, played imitating games; that is, imitating the superheroes in their favorite programs. Only one child, in addition to imitating fantasy characters, imitated football players. Examples include:

"I'm like Batman falling down the window" (boy, 6 years old)

"I'm very into role playing. First as a football player and then as the Spiderman and other cartoon characters" (boy, 8 years old)

None of the children who rarely watched fantasy animations mentioned imitating games based on fantasy characters. Only one participant mentioned an imitating game based on reality (pursuitevasion). All the children in this group mentioned physical games and sports such as football, volleyball, hide and seek, tag game, and playing with toy guns. Two cases mentioned, in addition to sports, intellectual games including puzzles and Sudoku.

\section{4- What do you think about more in your mind?}

14 children (of 17) who watched fantasy animations a lot, admitted that they thought about their favorite fantasy characters, and; some of the older children expressed they change the stories of the animations in their minds. Consider the following examples:

"I, for example, make a new episode of Avengers or Ultron Revival or, for example, Loki's Return, and imagine them in my mind over and over. I make and imagine them again and again. I change 


\section{$2^{\text {nd }}$ International Conference on Future of SOCIAL SCIENCES and HUMANITIES}

the story and imagine it. I change it too much that it's no longer The Age of Ultron but a very different story" (boy, 10 years old)

On the other hand, the children who watched fantasy animations a little thought about their favorite subjects, daily tasks, school, and what happens to them:

"I usually think of tomorrow to be a good day. I think about the positive things. I think tomorrow is a great day. It'll be fun for me. But unfortunately (laughing) it is as the day before. Nothing special happens, everything is as usual" (boy, 10 years old)

\section{5- Who is the person you would like to be like?}

The answers demonstrated that the children who watched fantasy cartoons a lot tended to be like their favorite characters in cartoons or have a part of their power or physical abilities. In fact, having "power" and becoming a "hero" was the common feature in all answers.

Consider the following answers:

"I'd like to be like Batman. I like Batman because he has power. If I had Batman's power, I would always win" (boy, 6 years old)

"I'd like to have the powers that I see in the movies. The same events would happen to me. For example, I would have the same capabilities to save someone. I'd like to have Benton's clock or Spiderman's power" (boy, 10 years old)

12 children out of 13 who watched fantasy animations a little, answered they like their real personality. That is, none of the children talked about fantasy activities and only one case who expressed his satisfaction with his real personality was interested in having superhuman powers, too. Unlike girls who wished to be changed and improved, boys in this group were satisfied with what they were and showed no desire to be changed. 


\section{$2^{\text {nd }}$ International Conference on Future of SOCIAL SCIENCES and HUMANITIES}

\section{6- What is the image of the future in your mind?}

15 children (of 17) in the first group wished a fantasy world and 2 others answered they liked the world as it is:

"I wish a world that all people have power like Spiderman" (boy, 6 years old)

10 children in the second group (13 children) said they liked the world as it is and 3 others wished for a different world. The desired changes for the three children were based on reality:

"I wish all people were nice. Now, some are nice and some aren't. (boy, 6 years old)

"No war" (boy, 10 years old)

"I wish people were more cultured, they didn't write anything on the walls, they didn't leave junk on the ground. I advise them to put junk in a bag. Why do they throw junk in nature? It takes two hundred years for plastic decomposition. I don't like to behave like them." (boy, 10 years old)

\section{Conclusion}

\section{Imitation; cognitive development in fantasy environment}

Imitation is one of the most important behaviors of children for extroversion and cognitive development. Children imagine a variety of situations and role play through imitating. These pretend plays increase their understanding of emotions and challenges in different situations. The results of our study showed that both girls and boys who watched fantasy animations a lot were more interested in imitating the heroes' actions through role playing. In fact, they are imitating the actions of the characters that do not exist in the real world. As Singer and Singer (1990) argued, the children's experience of engaging in a reality-based role playing may help them to differentiate reality from fantasy since children's ability to make changes helps them to understand not only the sequence and outcomes of the behaviors they produce themselves but also they can identify a sequence of those produced by others or are focused on the physical environment. Thus, cognitive development in children helps them to predict challenges and events during their life and if 


\section{$2^{\text {nd }}$ International Conference on Future of SOCIAL SCIENCES and HUMANITIES}

children fail to make such predictions correctly, they will be mistaken and may experience distress and anxiety.

\section{Increasing the difference between actual-self and ideal-self}

Our results showed that the children who watched fantasy animations a lot were keen to resemble fantasy characters or have their extraordinary powers or physical features. On the other hand, the children who rarely watched fantasy animations were more satisfied with the personality they had and some, who were older, expressed their desires to improve their skills in the future. In fact, the children who watched fantasy animations more than three hours a day experienced a big difference between their actual-self and their ideal-self while there was a lesser difference between actualself and ideal-self among children who watched fantasy animations a little. They also were more satisfied with their current personality. Moreover, the ideal self of the children in the first group was not achievable in the real world due to fantastic features and it can make them feel anxiety or stress in the future.

\section{A better world in the future}

As Piaget argued about stages of cognitive development, children begin to criticize the world at age 11 and freely imagine a better world. In the present study, children between 11 and 12 years old in both groups yearned to change the world in the context of reality. All of them criticized the status quo and desired a better world with development in technology, healthcare systems, and improved communications between people.

\section{Imagination in the context of fantasy}

Our results generally showed that the imagination of children who watched fantasy-oriented cartoons a lot was in the context of fantasy. The results of interviews showed that girls and boys (more than 11 years old) who watched fantasy animations a lot, imagined themselves with magical power in the future. They mentioned that we can overcome any problems in the future and make 


\section{$2^{\text {nd }}$ International Conference on Future of SOCIAL SCIENCES and HUMANITIES}

a better world. But children who watched fantasy animations a little imagined themselves and the future of the world in the context of reality and had accepted challenges in their lives.

\section{References}

Ariel, S. (2002). Children's Imaginative Play, A Visit to Wonderland. London: Child psychology and mental health.

Barrick, L. (2020). Interviews: In-Depth, Semistructured. International Encyclopedia of Human Geography (Second Edition), 403-408.

Brann, E. T. (1991). The world of the imagination (2017 ed.). Lanham: Rowman \& Litilefield Publishers.

Corbin, A. E. (1994). Grounded Theory Metodology. In N. K. Lincoln, Handbook of qualitative research. Thousand Oaks : Sage Publications.

DePoy, E. G. (2016). Introduction to Research: Understanding and Applying Multiple Strategies (5th Edition). Elsevier.

Gotz, M., Lemish, D., Aidman, A., \& Moon, H. (2005). Media and the make-believe worlds of children: when harry potter meets pokemon in disneyland. Mahwah: LAWRENCE ERLBAUM ASSOCIATES.

Havighurst, R. j., Robinson, M. Z., \& Dorr, M. (1946). The Development of the Ideal Self in Childhood and Adolescence. The Journal of Educational Research, 40(4), 241-257.

Helm, A. F., \& Spencer, R. M. (2019). Television use and its effects on sleep in early childhood. Journal of the National Sleep Foundation, 241-247.

Higgins, E. T. (1987). Self-Discrepancy: A Theory Relating Self and Affect. Psychological Review, 94(3), 319-340. 


\section{$2^{\text {nd }}$ International Conference on Future of SOCIAL SCIENCES and HUMANITIES}

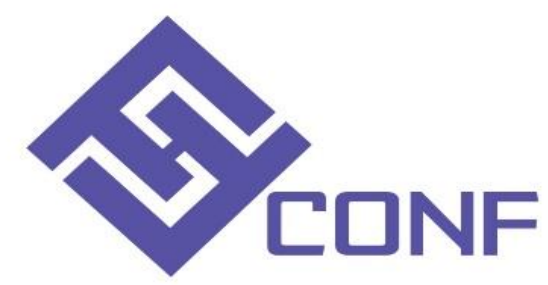

Messenger Davies, M. (1997). Fake, Fact, and Fantasy : Children's Interpretations of Television Reality. New York: Taylor \& Francis Inc.

Russ, S. W. (2020). Mind wandering, fantasy, and pretend play: a natural combination. In D. Preiss, D. Cosmelli, \& J. Kaufman, Creativity and the Wandreing Mind: Spontaneous and Controlled Cognition (pp. 231-248).

Schmitz, A., Joiner, R., \& Golds, P. (2020). Is seeing believing? The effects of virtual reality on young children's understanding of possibility and impossibility. Journal of Children and Media, 14(2), 158-172.

Sherrod, L. R., \& Singer, J. L. (2009). The Development of Make-Believe Play. In J. H. Goldstein, Sports, Games, and Play: Social and Psychological Viewpoints. London: Psychology Press.

Shqair, A. Q., Pauli, L. A., Costa, V. P., Cenci, M., \& Goettems, M. L. (2019). Screen time, dietary patterns and intake of potentially cariogenic food in children: A systematic review. Journal of Dentistry, 17-26.

Singer, D. G. (2003). Television and its potential for imagination.

Singer, D. G. (2005). Imagination and Play in the Electronic Age. United States of America: Harvard University Press.

Singer, J. L. (1981). Daydreaming and fantasy. New York: Oxford University Press.

Strauss, J. C. (2017). Basics of qualitative research. (E. Afshar, Trans.) Tehran: Ney.

Taggart, J., Eisen, s., \& Lillard, A. S. (2019). The current landscape of US children's television: violent, prosocial, educational, and fantastical content. Journal of Children and Media, 13(3), 276-294.

Tie, Y. C. (2019). Grounded theory research: A design framework for novice researchers. SAGE Open Med, 7, 1-8. 


\section{$2^{\text {nd }}$ International Conference on Future of SOCIAL SCIENCES and HUMANITIES}

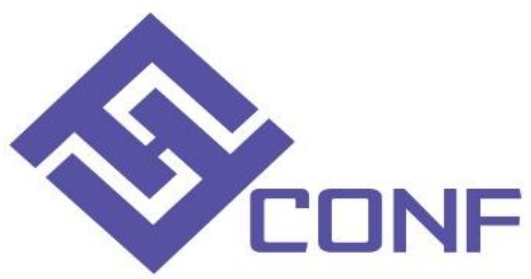

Valkenburg, P. M., \& van der Voort, T. H. (1994). Influence of TV on Daydreaming and Creative Imagination: A Review of Research. American Psychologica Association, 116(2), 316339.

Woodard, E. H., \& Gridina, N. (2000). Media in the Home, The Fifth Annual Survey of Parents and Children 2000. THE ANNENBERG PUBLIC POLICY CENTER OF THE UNIVERISTY OF PENNSYLVANIA, (pp. 1-41). 